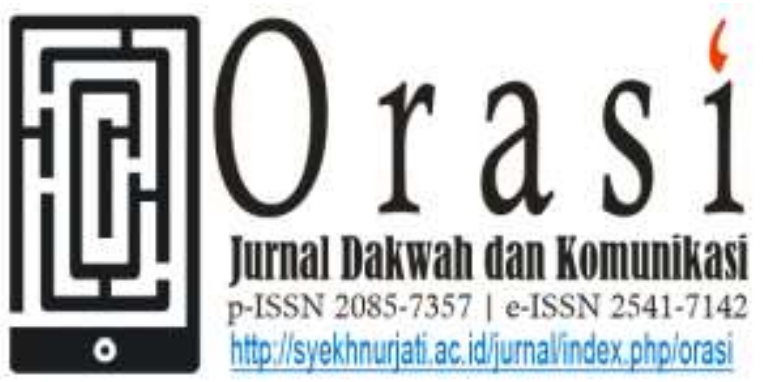

Volume 11 No. 1 Juli 2020

\title{
PENERIMAAN KHALAYAK TERHADAP KONSTRUKSI MILLENNIAL PARENTING DI INSTAGRAM PARENTALK.ID
}

\section{AUDIENCE ACCEPTANCE OF MILLENNIAL PARENTING CONSTRUCTION ON INSTAGRAM PARENTALK.ID}

\author{
Soraya Ratna Pratiwi,a) \\ ${ }^{1}$ Program Studi Ilmu Komunikasi, Fakultas Industri Kreatif, Institut Teknologi dan Bisnis Kalbis \\ J1. Pulomas Selatan Kav. 22, Jakarta Timur \\ a)e-mail:sorayapratiwi@gmail.com
}

\begin{abstract}
ABSTRAK
Orang tua millennial memiliki pola asuh yang berbeda dengan pola asuh pada generasi sebelumnya. Millenial yang menjadi orang tua tidak lagi percaya terhadap pola asuh yang melibatkan mitos atau pun informasi pola asuh yang diragukan sumbernya. Parentalk hadir dengan visi dan misi membantu orang tua millennial untuk terhubung, mendapatkan inspirasi, dan membagikan cerita mereka tentang pengasuhan. Parentalk merupakan media yang berfokus pada konten untuk orang tua millenial. Penelitian ini bertujuan untuk mengetahui respon dan posisi khalayak, yaitu orang tua milenial terhadap informasi millennial parenting di Instagram @Parentalk.id. Penelitian ini dilaksanakan dengan pendekatan kualitatif dan menggunakan konsep decoding-encoding Stuart Hall. Data penelitian didapat dengan melakukan wawancara dan literature terkait. Adapun hasil penelitian menyatakan bahwa posisi informan berbeda-beda berdasarkan latar belakang dan kondisi keluarga masing-masing, namun posisi khalayak didominasi oleh hegemoni dominan. Hal ini cukup menjelaskan bahwa informasi yang diberikan oleh Parentalk berarti dimaknai sama dan sejalan dengan khalayak. Ditemukan juga bahwa khalayak memang aktif dalam mengkonsumsi informasi yang disajikan media. Aktif di sini maksudnya adalah bahwa khalayak memiliki kuasa dalam memilih media yang dipakainya untuk mengakses informasi. Berdasarkan hasil wawancara, informan memiliki preferensinya sendiri ketika mencari informasi terkait pola asuh anak (parenting). Saluran komunikasi yang umumnya digunakan oleh informan adalah Instagram, internet, orangtua, dokter, dan juga suami.
\end{abstract}

Kata Kunci: Millennial Parenting, Parentalk, Penerimaan Khalayak, Pola Asuh, Resepsi 


\begin{abstract}
Millennials have a parenting style that is different from parenting in the previous generation. Millennials who become parents no longer believe in parenting that involves myths or parenting information whose source is doubtful. Parentalk comes with a vision and mission to help millennial parents connect, get inspiration, and share their stories about parenting. Parentalk is a media that focuses on content for millennial parents. This study aims to determine the response and position of the audience, namely millennial parents to millennial parenting information on Instagram @ Parentalk.id. This research was conducted with a qualitative approach and using the Stuart Hall decoding-encoding concept. Research data obtained by conducting interviews and related literature. The results of the study stated that the position of the informants varied based on their background and family conditions, but the position of the audience was dominated by dominant hegemony. This is sufficient to explain that the information provided by Parentalk means the same meaning and in line with the audience. It was also found that the audience was indeed active in consuming information presented by the media. Active here means that the public has the power to choose the media they use to access information. Based on the results of the interviews, the informants have their own preferences when looking for information related to parenting. The communication channels commonly used by informants are Instagram, the internet, parents, doctors, and also husbands.
\end{abstract}

Keywords: Audience Acceptance, Millennial Parenting, Parentalk, Parenting, Reception

\section{Pendahuluan}

Generasi millennial identik dengan karakternya yang berani, spontan, menyukai hal yang praktis, dan kritis. Begitu pula yang terjadi pada orang tua millennial, yaitu generasi millennial yang menjadi orang tua. Orang tua millennial memiliki pola asuh yang berbeda dengan pola asuh pada generasi sebelumnya. Gunarsa (2002) mengatakan bahwa pola asuh merupakan cara orangtua bertindak sebagai orangtua terhadap anakanaknya di mana mereka melakukan serangkaian usaha aktif (Adawiah 2017). Pola asuh sendiri dipengaruhi oleh beberapa factor menurut Hurlock (1999), yakni factor kepribadian orang tua, keyakinan, dan persamaan dengan pola asuh yang diterima orang tua. Tapi, apabila pola asuh yang digunakan oleh orangtua dirasa tidak tepat, maka orang tua akan memilih teknik pola asuh yang lain disesuaikan dengan usia orangtua, pendidikan, jenis kelamin, status sosial ekonomi, dan lain-lain (Adawiah 2017).

Millenial yang menjadi orang tua tidak lagi percaya terhadap pola asuh yang melibatkan mitos atau pun informasi pola asuh yang diragukan sumbernya.Kelompok yang tergabung ke dalam generasi millennial ini adalah generasi muda yang saat ini memiliki rentang umur 15- 34 tahun. Berdasarkan laporan NRC Health (Nrchealth.com 2017) menyebutkan bahwa orang tua millennial menggunakan internet sebagai langkah pertama untuk memilih penyedia layanan kesehatan atau rumah sakit. Generasi millennial mengandalkan komputer, yang mana generasi sebelumnya cenderung menggunakan telepon. Mereka lebih nyaman 
mencari riset, rekomendasi, dan ulasan melalui internet dan media sosial.

Berdasarkan survey yang diselenggarakan oleh JAKPAT, sebanyak 98.8\% responden melaporkan bahwa mereka menggunakan internet untuk mencari informasi mengenai anaknya. Informasi yang paling banyak dicari di internet dan menempati posisi teratas adalah kesehatan anak dan di posisi kedua, adalah informasi mengenai pendidikan anak (Jakpat 2018).

Era digital berdampak tidak hanya pada orangtua, melainkan juga pada kondisi anak. Tidak sedikit anak yang gemar bermain gadget dan meninggalkan aktivitas fisik yang sebenarnya bisa membantu perkembangan mereka. Era digital juga 'memberikan' anak kebebasan untuk memilih hiburannya sendiri. Sehingga mengasuh anak di era digital penuh dengan tantangan. Dalam hal ini, diperlukan kesiapan orangtua, terutama ibu, untuk menghadapinya. Seiring perubahan zaman, pola asuh pun turut berubah, menyesuaikan bentuk pengasuhan yang diterapkan, yang biasanya tidak bisa lagi menerapkan pola asuh tradisional. Orangtua, terutama ibu dihadapkan pada tantangan untuk menambah pengetahuannya tentang teknologi digital agar bisa mengikuti perkembangan zaman (Hildayani 2018).

Orangtua bertanggungjawab dalam memberikan pola asuh yang baik dan tepat. Karena, pengasuhan yang tidak tepat dan keterampilan pengasuhan yang buruk dapat meningkatkan stres pada anak. Apabila anak terlalu ditekan atau sebaliknya terlalu dibebaskan, maka akan mengilangkan kesempatan pada anak untuk belajar bertanggung jawab dan berkembang menjadi anak yang mampu bersosialisasi dengan baik (Hildayani 2018).

Penelitian lain mengenai parenting menyatakan bahwa salah satu cara / pola asuh yang dapat dilakukan oleh orangtua adalah dengan melakukan mindful parenting. Mindful parenting mengacu orang tua yang mengedapankan kesadaran dalam mengasuh buah hati mereka dan melakukan pengendalian emosi (Lisa dan Astuti 2018).

Seakan membaca kebutuhan orang tua millennial, Parentalk hadir dengan visi dan misi membantu orang tua millennial untuk terhubung, mendapatkan inspirasi, dan membagikan cerita mereka tentang pengasuhan. Parentalk merupakan media yang berfokus pada konten untuk orang tua millenial. Parentalk berdiri sejak November 2017 dan penyebaran kontennya dilakukan melalui tiga platform internet, yaitu Instagram, Youtube, dan Facebook. Parentalk memiliki pertumbuhan pengikut yang cukup cepat di Instagram. Konten Instagram Live menjadi salah satu ciri khas dari Parentalk sejauh ini (Eka 2017). 


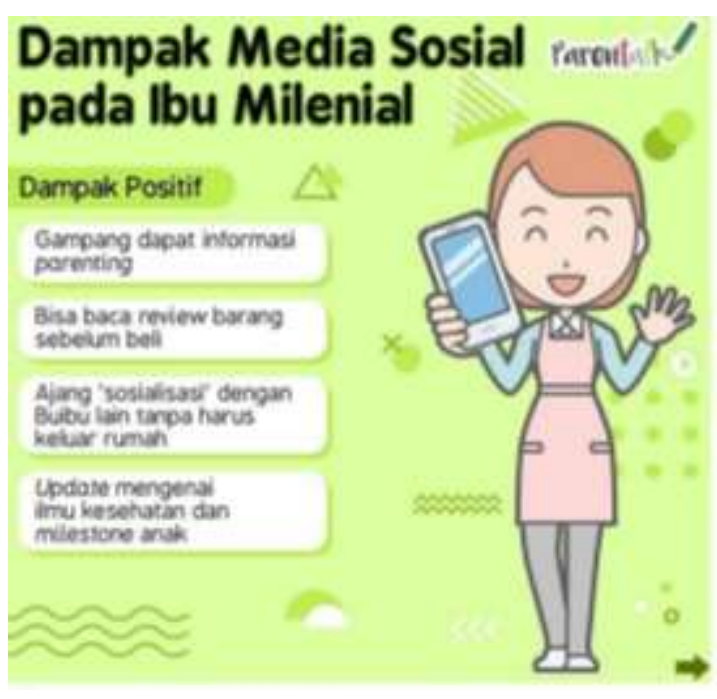

Gambar 1. Salah Satu Konten Parentalk.Id di Instagram

Parentalk aktif memberikan informasi serta tips untuk orang tua millennial, dengan menggunakan tagar andalannya yakni \#MillennialParenting. Melalui kontenkontennya, Parentalk berani 'mendobrak' pola asuh lama yang masih mengacu pada mitos. Parentalk menggunakan media siber untuk menjangkau generasi millennial karena fokusnya yang kuat pada media sosial. Konten yang dibuat oleh Parentalk.Id mengkonstruksikan gambaran bagaimana orangtua milenial berperilaku. Dari mulai pola asuh anak, berkomunikasi dengan pasangan, pengembangan diri sebagai orangtua milenial, dan aktivitas lainnya.

Berdasarkan latar belakang tersebut, penulis tertarik untuk mengkaji bagaimana orang tua millenials memaknai dan menerima informasi mengenai pola asuh yang diberikan oleh Parentalk di akun Instagramnya. Terutama apabila mereka dihadapkan pada informasi yang tidak sesuai dengan nilai-nilai yang mereka anut.
Adapun tujuan penelitian ini adalah untuk mengetahui posisi orangtua milenial terhadap konstruksi millennial parenting di Instagram Parentalk.id dan mengetahui faktor yangmempengaruhi posisi orangtua milenial terhadap konstruksi millennial parentingdi Instagram Parentalk.Id.

Tujuan penelitian sejalan dengan asumsi yang dikemukakan teori encodingdecoding, yang dicetuskan oleh Stuart Hall. Menurut Hall dijelaskan bahwa media memiliki dominasi terhadap khalayak. Ia menegaskan bahwa khalayak memaknai kodekode pesan yang dikirim oleh media, kemudian ditentukan posisi khalayak terhadap ideology media tersebut tergantung dari kesiapan maupun penerimaan khalayak terhadap pesan. Di sini, pemaknaan khalayak turut dipengaruhi oleh pengetahuan, ideology, dan asumsi dari khalayak itu sendiri. Lebih lanjut, Hall menjelaskan bahwa media berusaha membentuk gambaran, topik, bahkan agenda terhadap khalayak terkait dengan kultur sosial maupun struktur politik (Nasrullah 2019).

Dalam teori ini dijelaskan bahwa pesan sebelum ditransmisikan menjadi kodekode (proses encoding) akan melaui serangkaian perangkat bahasa agar dapat direalisasikan atau dimaknai kembali (proses decoding). Sebuah pesan seharusnya dapat dimaknai ulang secara sama sebagaimana pesan tersebut dikodekan di awal. Proses pengodean dan penerjemahan pesan ini bergantung pada struktur dari praktik-praktik sosial yang ada (Nasrullah 2019). 
Hall mengidentifikasi tiga posisi audiens dalam memecahkan kode pesan, yang terdiri dari: posisi dominan, posisi dinegosiasi, dan posisi oposisi (During 1999).

\section{a. Dominant-hegemonic position}

Ketika audiens memaknai dan memahami pesan seluruhnya secara apa adanya dan melakukan decoding pesan sesuai dengan encoding yang diberikan, dapat dikatakan bahwa audiens berada dalam posisi dominan-hegemonis. Hal ini dianggap sebagai case atau kejadian yang ideal, di mana komunikasi berjalan 'transparan' dan sesuai dengan yang diinginkan pengirim pesan.

\section{b. Negotiated position}

Posisi dimana khalayak dianggap cukup memahami pesan yang sudah ada dan didefinisikan secara dominan, tetapi di sisi lain audiens juga tidak menerima semua pesan yang dimaksudkan oleh encoder. Khalayak sampai batas tertentu menerima makna yang cocok bagi mereka, namun juga secara bersamaan menolak pesan berdasarkan preferensi (pengalaman dan minat) dari masing-masing khalayak).

\section{c. Oppositional Position}

Dalam posisi ini khalayak memahami arti pesan sebenarnya. Tapi, karena berbeda latar belakang, maka masing-masing individu / khalayak memiliki caranya sendiri dalam melakukan decoding pesan dan membentuk interpretasinya sendiri yang bertolakbelakang dari makna yang dimaksud. Khalayak melakukan decoding pesan dengan mengacu pada beberapa referensi alternatif.

\section{Metodologi Penelitian}

Pendekatan yang digunakan dalam penelitian ini adalah kualitatif, yang mana merupakan penelitian berdasarkan fenomena di lapangan dan kemudian dianalisis. Adapun objek pada penelitian ini adalah informasi mengenai millennial parenting di Instagram @ parentalk.id. Data primer dikumpulkan melalui pihak terkait menggunakan teknik wawancara mendalam. Wawancara dilakukan kepada delapan narasumber yang merupakan pengikut Instagram @ Parentalk.id, yang terdiri dari AF, SM, MU, CH, AT, HN, FD, dan MY. Peneliti juga menggunakan pencarian informasi melalui buku, jurnal, website resmi Parentalk, media online, dan dokumendokumen lain yang terkait dengan millennial parenting.

Salah satu cara untuk mengukur khalayak media adalah menggunakan analisis resepsi (reception analysis). Analisis resepsi mencoba untuk memberikan gambaran atas sebuah pemaknaan dan pemahaman teks media yang dibaca oleh khalayak, baik dalam bentuk cetak, elektronik, maupun internet (Hadi 2008). Riset khalayak menurut Stuart Hall (1973) memfokuskan pada: (a) analisis dalam konteks sosial dan politik dimana isi media diproduksi (encoding); dan (b) konsumsi isi media (decoding) dalam konteks kehidupan sehari-hari. Analisis resepsi memfokuskan pada perhatian individu dalam proses komunikasi massa (decoding), yaitu pada proses pemaknaan dan pemahaman yang mendalam atas media texts, dan bagaimana individu menginterpretasikan isi media (Hadi 2008). 


\section{Hasil dan Pembahasan}

Milennial parenting memiliki makna yang berbeda-beda bagi setiap informan. Tapi, apabila ditarik garis besarnya, pemaknaan mereka terhadap millennial parenting memiliki satu kesamaan, yaitu pola pengasuhan yang modern, terbuka, dan bersikap berdasarkan fakta, bukan sekedar mitos.

Parentalk.Id menyediakan konten mengenai kehamilan, bayi, balita, dan pola asuk (parenting) di berbagai platform digital bagi para orang tua millennial baru. Kehadiran Parentalk adalah untuk membantu orang tua millennial supaya terhubung, mendapatkan inspirasi, dan membagikan cerita mereka mengenai pola asuh anaknya. Tujuan tersebut sesuai dengan kebutuhan orang tua millennial, yang mana di era disrupsi seperti ini, informasi yang beredar simpang siur dan sulit menemukan informasi yang kredibel.

Salah satu informan mengatakan bahwa dirinya mengikuti akun Parentalk di Instagram karena kontennya menarik dan sesuai dengan kehidupan sehari-hari, seperti: tentang rumah tangga, hubungan dengan pasangan (suami), pengasuhan anak, menyusui, dan lain-lain.

\section{Konten yang dimiliki Parentalk} didapat setelah melewati riset konsumen terlebih dahulu. Oleh karena itu, ada kemungkinan bahwa pembaca akan merasakan konten yang disampaikan oleh Parentalk sesuai dengan keadaan dirinya sehari-hari, meskipun tidak semuanya. Hal ini juga yang diungkapkan oleh informan bahwa dirinya merasa konten Parentalk cukup menggambarkan keadaan yang dialaminya sebagai orang tua muda.

Pada sesi wawancara, peneliti menunjukkan beberapa konten @Parentalk.Id di Instagram, yang peneliti nilai bahwa konten tersebut menunjukkan dan mengkonstruksi millennial parenting dibandingkan dengan konten lainnya. Sehingga, pada hasil penelitian ini dibagi menjadi beberapa kategori.

Hall mengidentifikasi tiga posisi audiens dalam memecahkan kode pesan, yang terdiri dari: posisi dominan, posisi dinegosiasi, dan posisi oposisi (During 1999). Dalam penelitian ini, Parentalk sebagai media yang aktif memberikan tips kepada khalayaknya, mencoba untuk mengkonstruksi pola asuh yang baik dan ideal bagi orang tua millennial. Menggunakan tagar \#millennialparenting, terkadang konten yang dibagikanpun mencoba untuk meruntuhkan mitos-mitos yang sering ditemukan dalam mendidik anak. Parentalk berusaha untuk memberikan pandangan baru dan solusi bagi khalayaknya. Dengan demikian, informan sebagai khalayak dan follower yang sudah lama mengikuti Parentalk di Instagram, mencoba memaknai pesan-pesan dari konten Parentalk. Hasilnya, khalayak berada di posisi yang berbeda-beda dan akan dijelaskan melalui bagan di bawah ini. 


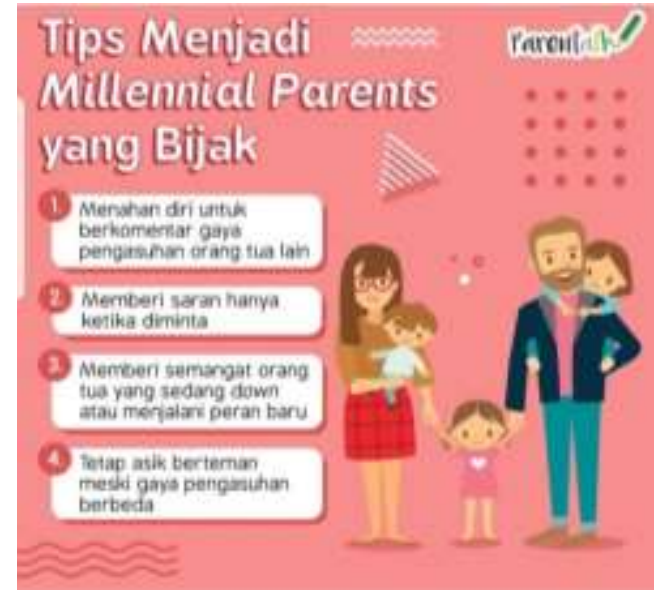

Gambar 2. Tips Menjadi Millennial Parents yang Bijak

Gambar 2 di atas menunjukkan tips bagaimana menjadi orangtua millennial yang bijak. Sebanyak tujuh informan menyatakan dirinya sepakat dan memahami maksud konten tersebut. Mereka juga sudah merasa menjalankan pola asuh yang sesuai dengan tips di dalam konten. Satu orang (MY) merasa dirinya masih berusaha menjadi orangtua yang digambarkan dalam konten, namun ia mengakui bahwa tips di dalam konten bagus untuk dilakukan sehari-hari. Dengan demikian, dapat dikatakan tujuh orang berada di posisi hegemoni dominan dan satu orang berada di posisi negosiasi.

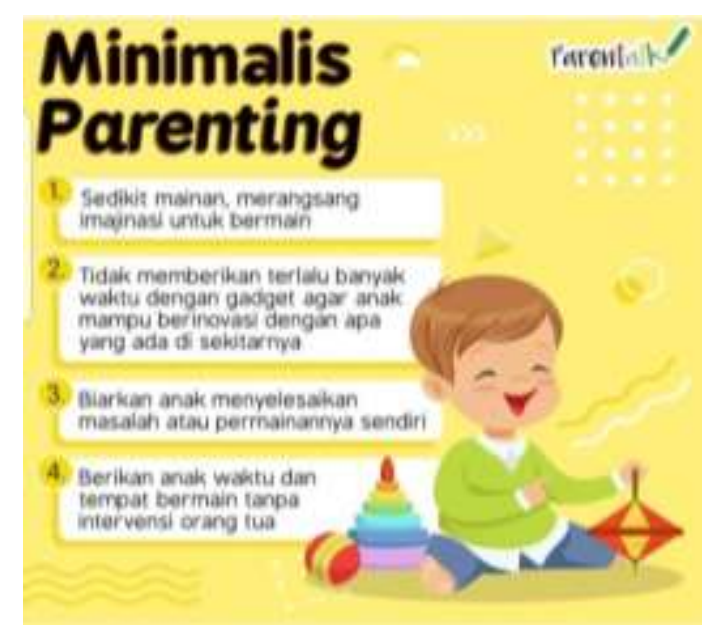

Gambar 3. Minimalis Parenting
Pada gambar 3, dijelaskan pola asuh minimalis (minimalist parenting)yang apabila dinilai lebih jauh, pola asuh minimalis ini mengedepankan kemandirian anak untuk menjalani kegiatannya sehari-hari. Berbeda dengan konten di gambar 2, gambar 3 ini mendapati posisi khalayak lebih banyak di posisi negosiasi, dengan jumlah informan sebanyak lima orang. Sisanya, tiga orang berada di posisi hegemoni dominan.

Khalayak dikategorikan pada posisi negosiasi ketika khalayak sampai batas tertentu menerima makna yang cocok bagi mereka, namun juga secara bersamaan menolak pesan berdasarkan preferensi (pengalaman dan minat) dari masing-masing khalayak. Contohnya, AT dan MU yang berada di posisi negosiasi karena mereka sama-sama tidak dapat menerapkan pola asuh minimalis secara penuh sesuai dengan petunjuk konten tersebut. Mereka mempertimbangkan mana yang dapat diaplikasikan pada anaknya, mengingat umur dan kondisi anaknya yang masih butuh pengawasan penuh dari orangtua. Berbeda dengan $\mathrm{AF}, \mathrm{CH}$ dan SY yang menerima penuh pesan minimalis parenting karena mereka sudah dan mampu menerapkan pola asuh tersebut dalam kesehariannya. 


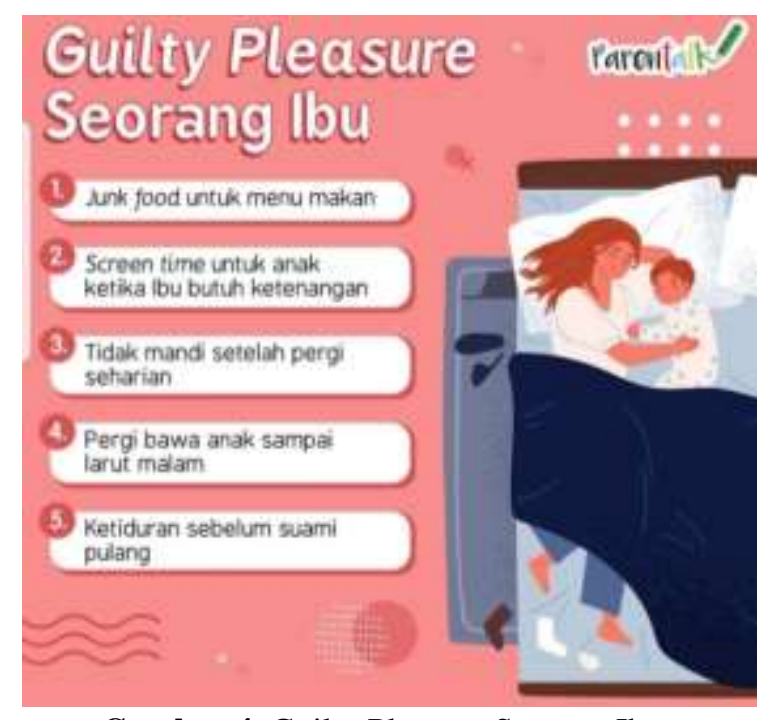

Gambar 4. Guilty Pleasure Seorang Ibu

Gambar 4 menjelaskan apa saja guilty pleasure seorang ibu yang terdiri dari: memberikan junk food untuk makan anak, memberikangadget pada anak saat ibu butuh ketenangan, tidak mandi setelah bepergian, mengajak anak bepergian sampai larut malam, dan tertidur sebelum suami pulang. Sebanyak empat orang dikategorikan pada posisi hegemoni dominan, tiga orang pada posisi negosiasi, dan satu orang pada posisi oposisi.

Pada kategori hegemoni dominan, informan menilai bahwa konten tersebut mencerminkan diri mereka sebagai seorang ibu. Salah satu informan yang berada pada posisi tersebut pun mengatakan bahwa bahasan dalam konten 'Guilty Pleasure Seorang Ibu' lumrah dilakukan oleh para ibu, karena biasanya dilakukan bukan karena disengaja, melainkan memiliki alasan di baliknya.

Pada posisi negosiasi, tiga orang informan beranggapan bahwa tidak semua bahasan dalam konten 'Guilty Pleasure Seorang Ibu' boleh dilakukan. Pemaknaan khalayak turut dipengaruhi oleh pengetahuan, ideologi, dan asumsi dari khalayak itu sendiri. Sehingga, wajar apabila setiap konten dimaknai berbeda dan menghasilkan posisi khalayak yang berbeda pula. Menurut MY, dirinya tidak setuju dengan point memberikan junk food pada anak. Hal ini bertentangan dengan prinsip yang ia miliki. MY juga mengatakan bahwa dalam mengambil keputusan untuk anaknya, ia selalu berdiskusi dengan suami. Sama halnya dengan HN, beberapa point yang digambarkan pada konten tidak sejalan dengan prinsip yang ia anut bersama suami.

Sedangkan pada posisi oposisi, SY mengatakan bahwa konten "guilty pleasure seorang ibu' ini mencerminkan orangtua millennial, tapi ia tidak sepakat dengan bahasan pada konten tersebut. Menurutnya, konten tersebut menggambarkan kebiasaan yang buruk bagi seorang istri karena akan berdampak tidak baik bagi anak dan keluarga di rumah. Ia juga merupakan tipikal orangtua yang menjauhi junk food karena selain tidak sehat, makanan tersebut juga menghabiskan (pemborosan) pengeluaran sehari-hari. Hal ini bisa saja terjadi karena ia seorang ayah, sehingga tidak merasakan/ melakukan peran sebagai ibu dalam mengurus anak. 

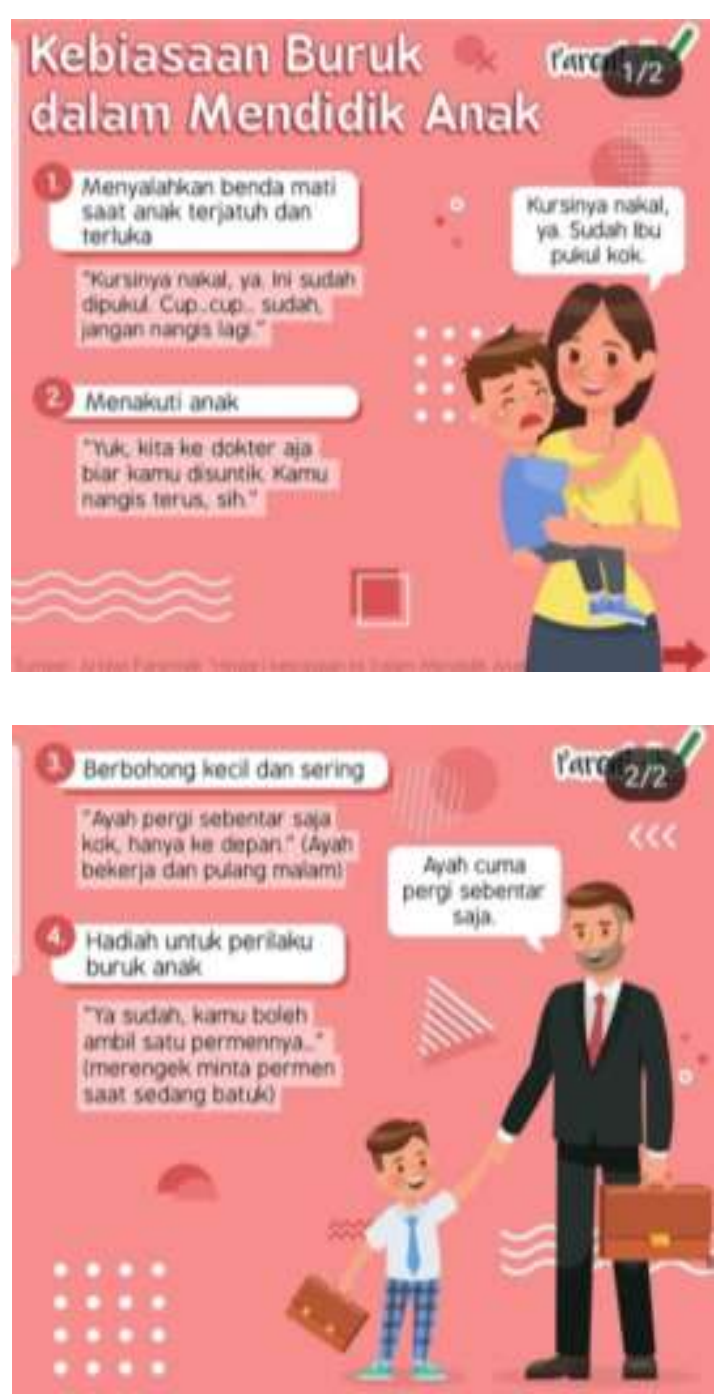

Gambar 5. Kebiasaan Buruk dalam Mendidik Anak

Gambar 5 menjelaskan 'Kebiasaan Buruk Dalam Mendidik Anak' misalnya berbohong kepada anak, menakuti anak, menyalahkan benda mati saat anak jatuh dan terluka, serta memberikan hadiah untuk perilaku buruk anak. Khalayak pada posisi hegemoni dominan, yang mana berjumlah empat orang menilai bahwa mereka sepakat dengan isi yang dipaparkan. Konten tersebut menunjukan contoh kebiasaan buruk dalam mendidik anak yang biasa dilakukan sebagian orang tua, orang tua perlu memperhatikan ini agar terhindar dari kebiasaan buruk tersebut yang bisa mempengaruhi tumbuh kembang anak. AT beranggapan bahwa konten ini sangat bermanfaat untuk terus mengingatkan kepada orangtua millenial bahwa cara mendidik seperti ini hanya berlaku dijaman orang tua jaman dulu yang minim informasi bahwa cara mendidik seperti ini membawa dampak negatif untuk tumbuh kembang anak.

Hal yang sama diutarakan oleh MT yang tidak memiliki perbedaan cara pandang dengan bahasan yang diberikan. Ia sepakat dengan Parentalk yang mengatakan bahwa perilaku menakut-nakuti anak dan mengancam anak adalah cara mendidik yang buruk. Menurutnya, walau masih kecil, anak-anak patut diperlakukan sama, sebagai awal membentuk pribadi anak dan cara komunikasi anak.

Sedangkan pada posisi negosiasi, FD merasa tidak sepakat dengan sebagian bahasan yang diberikan. Baginya, ia masih perlu menerapkan ancaman pada anak apabila anaknya sulit diatur. Namun, ia juga menambahkan bahwa hal tersebut ia lakukan hanya dalam kondisi tertentu yang membuatnya mau tidak mau mengancam anak atau menakut-nakuti anak. Begitu juga dengan $\mathrm{AF}$, ia tidak menerima sebagian poin-point yang dibahas dalam konten. Terdapat beberapa perbedaan dengan perilakunya sehari-hari sebagai orangtua.

Berdasarkan pemetaan posisi khalayak di atas, khalayak menerima pesan Parentalk dengan cara yang berbeda, berdasarkan latar belakang dan kondisi keluarga masing-maisng. Ditemukan juga bahwa khalayak memang aktif dalam mengkonsumsi informasi yang 
disajikan media. Aktif di sini maksudnya adalah bahwa khalayak memiliki kuasa dalam memilih media yang dipakainya untuk mengakses informasi. Berdasarkan hasil wawancara, informan memiliki preferensinya sendiri ketika mencari informasi terkait pola asuh anak (parenting). Saluran komunikasi yang umumnya digunakan oleh informan adalah Instagram, internet, orangtua, dokter, dan juga suami. Hal ini sejalan dengan konsep aktivitas khalayak yang dicetuskan oleh Levy dan Windahl (dalam Wets dan Turner 2008). Mereka menjelaskan konsep aktivitas khalayak dan bagaimana khalayak melakukan seleksi terhadap konten media yang digunakannya. Khalayak dianggap aktif, artinya khalayak memiliki kuasa atas pemilihan media yang akan digunakannya dalam rangka pemenuhan kebutuhan khalayak itu sendiri (Nasrullah 2019). Di mana kondisi ini melibatkan pula aspek psikologis dari khalayak dan bisa dipahami juga pemrosesan informasi atau mengkonstruksi informasi dalam upaya membangun makna dari setiap pesan yang diterima.

Tabel 1. Hasil Pemetaan Khalayak

\begin{tabular}{lllll}
\hline & $\begin{array}{c}\text { Menjadi } \\
\text { Millennial } \\
\text { Parents } \\
\text { yang Bijak }\end{array}$ & $\begin{array}{l}\text { Minimalis } \\
\text { Parenting }\end{array}$ & $\begin{array}{c}\text { Guilty } \\
\text { Pleasure } \\
\text { Seorang } \\
\text { Ibu }\end{array}$ & $\begin{array}{c}\text { Kebiasaan } \\
\text { Buruk } \\
\text { dalam } \\
\text { Mendidik } \\
\text { Anak }\end{array}$ \\
\hline AF & $\begin{array}{l}\text { Hegemoni } \\
\text { dominan }\end{array}$ & $\begin{array}{l}\text { Hegemoni } \\
\text { dominan }\end{array}$ & negosiasi & Negosiasi \\
\hline SM & $\begin{array}{l}\text { Hegemoni } \\
\text { dominan }\end{array}$ & $\begin{array}{l}\text { Hegemoni } \\
\text { dominan }\end{array}$ & oposisi & Negosiasi \\
\hline MU & $\begin{array}{l}\text { Hegemoni } \\
\text { dominan }\end{array}$ & negosiasi & $\begin{array}{l}\text { Hegemoni } \\
\text { dominan }\end{array}$ & $\begin{array}{l}\text { Hegemoni } \\
\text { dominan }\end{array}$ \\
\hline CH & Hegemoni & Hegemoni & Hegemoni & Hegemoni
\end{tabular}

\begin{tabular}{clcll} 
& dominan & dominan & dominan & dominan \\
\hline AT & $\begin{array}{l}\text { Hegemoni } \\
\text { dominan }\end{array}$ & negosiasi & $\begin{array}{l}\text { Hegemoni } \\
\text { dominan }\end{array}$ & $\begin{array}{l}\text { Hegemoni } \\
\text { dominan }\end{array}$ \\
\hline HN & $\begin{array}{l}\text { Hegemoni } \\
\text { dominan }\end{array}$ & negosiasi & negosiasi & $\begin{array}{l}\text { Hegemoni } \\
\text { dominan }\end{array}$ \\
\hline FD & $\begin{array}{l}\text { Hegemoni } \\
\text { dominan }\end{array}$ & negosiasi & $\begin{array}{l}\text { Hegemoni } \\
\text { dominan }\end{array}$ & Negosiasi \\
\hline MY & Negosiasi & negosiasi & negosiasi & Negosiasi \\
\hline
\end{tabular}

\section{Simpulan dan Saran}

Berdasarkan teori encoding-decoding yang dicetuskan oleh Stuart Hall, maka didapat posisi khalayak yang berbeda-beda dari setiap konten yang Parentalk yang telah dipilih. Khalayak menduduki posisi yang berbeda didasari oleh latar belakangnya, prinsip yang dianutnya sebagai orang tua, agama, dan pengaruh dari pasangan,namun posisi khalayak didominasi oleh hegemoni dominan. Hal ini cukup menjelaskan bahwa informasi yang diberikan oleh Parentalk berarti dimaknai sama dan sejalan dengan khalayak.Ditemukan juga bahwa khalayak memang aktif dalam mengkonsumsi informasi yang disajikan media. Mereka memiliki preferensi sendiri ketika memilih media yang dipakainya untuk mengakses informasi. Berdasarkan hasil wawancara, informan memiliki preferensinya sendiri ketika mencari informasi terkait pola asuh anak (parenting). Saluran komunikasi yang umumnya digunakan oleh informan adalah Instagram, internet, orangtua, dokter, dan juga suami.

Berikut adalah saran yang diberikan peneliti untuk penelitian lanjutan: (1) Penelitian sejenis dapat mengevaluasi dampak atau pengaruh dari konten Parentalk terhadap perubahan perilaku khalayak, agar penjelasan 
yang didapat mampu melengkapi penelitian ini. (2) Peneliti juga menyarankan untuk melakukan penelitian langsung kepada pihak Parentalk agar temuan yang didapat menghasilkan temuan yang lebih menyeluruh (holistic) dari kedua belah pihak, baik dari pihak Parentalk sebagai pemberi informasi dan pihak khalayak sebagai penerima informasi.

\section{Daftar Pustaka}

Adawiah, Rabiatul. 2017. "Pola Asuh Orang Tua dan Implikasinya Terhadap Pendidikan Anak (Studi Pada Masyarakat Dayak di Kecamatan Halong Kabupaten Balangan)." Jurnal Pendidikan Kewarganegaraan 7 (1): 33 48.

https://ppjp.ulm.ac.id/journal/index.php/p $\mathrm{kn} /$ article/view/3534

During, Simon. 1999. The Cultural Studies: Second Edition. London: Routledge.

Eka, Randi. 2017. "Parentalk merupakan media yang berfokus pada konten untuk orang tua millennial." Dailysocial.id. https://dailysocial.id/post/parentalkmenerima-pendanaan-awal-dari-emerakapital

Hildayani, Rini. 2018. Millennial Parenting dan Peranannya Terhadap Kesehatan Pencernaan. UI Publishing, pp. 298-315.

Hurlock, E.B. 1999. Chlid Development Jilid II, terjemahan Tjandrasa. Jakarta: Erlangga.

Jakpat. 2018. "Digital Parenting: The Habit of Online Information Seeking." Blog.jakpat.net. https://blog.jakpat.net/digital-parenting/

Lisa, Warda dan Asagaya Astuti. 2018. "Perbedaan Pengasuhan Berkesadaran pada Orang Tua Milenial." Jurnal
Psikologi $11 \quad$ (1): $\quad$ 60-71. https://ejournal.gunadarma.ac.id/index.ph p/psiko/article/view/2074

Nasrullah, Rulli. 2017. Media Sosial: Perspektif Komunikasi, Budaya, dan Sosioteknologi. Bandung: Simbiosa Rekatama Media.

Nrchealth.com. 2017. "Millennial Parents: Challenging Conventional Expectations of Pediatric Care." Nebraska. https://nrchealth.com/resource/challengin g-convention-millennial-parentsexpectations-pediatric-care/.

Wets, Richard dan Lynn H. Turner. 2008. Pengantar Teori Komunikasi: Analisis dan Aplikasi. Jakarta: Salemba Humanika. 
(Sengaja dikosongkan untuk kebutuhan pengaturan tata letak jurnal)

Orasi: Jurnal Dakwah dan Komunikasi | Volume 11, No. 1, Juli 2020 